\title{
SEGREGAÇÃO SOCIOESPACIAL E DIREITO À CIDADE: UMA ANÁLISE DO SETOR SUDESTE DE CASTANHAL-PA
}

\author{
SOCIO-SPATIAL SEGREGATION AND THE RIGHT TO THE CITY: \\ AN ANALYSIS OF THE SOUTHEASTERN SECTOR OF CASTANHAL-PA
}

\author{
SEGREGACIÓN SOCIOESPACIAL Y DERECHO A LA CIUDAD: \\ UN ANÁLISIS DEL SECTOR SURESTE DE CASTANHAL-PA
}

\section{RESUMO}

\author{
Anderson de Sousa CARVALHO ${ }^{1}$ \\ Jhon Cleber Moraes da SILVA ${ }^{2}$ \\ Rayan Valter Oliveira CARRERA ${ }^{3}$ \\ Willame de Oliveira RIBEIRO ${ }^{4}$
}

Castanhal localiza-se no nordeste do estado do Pará, nos últimos anos passou por uma considerável expansão de sua malha urbana a partir docrescimento de suas áreas periféricas. Este é o caso do setor sudeste da cidade (lócus da pesquisa), que contou para sua estruturação com forte atuação dos grupos sociais precariamente incluídos, por meiode ocupações, sendo frutos dessas os bairros Jaderlândia e Heliolândia. Mais recentemente, esse setor sudeste vem sendo foco de políticas habitacionais do Estado e de promotores imobiliários privados, como exemplifica o empreendimento Jardim das Flores. Nessa perspectiva, a pesquisa objetivoureconhecer o contexto socioespacial do setor sudeste de Castanhal, bem como compreender a inserção dos seus residentes na cidade. Por meio de levantamentos teóricos, documentais e de campo, com a aplicação de entrevistas, pôde-se constatar que os moradoresdessa área de Castanhal, marcada pela precariedade de suas infraestruturas e serviços, possuem também precária inserção no contexto urbano, o que se relaciona diretamente à manifestação do processo de segregação socioespacial e, por conseguinte, distancia seus residentes do direito à cidade.

Palavras-chave: segregação socioespacial, direito à cidade, sudeste de Castanhal-PA.

\begin{abstract}
Castanhal is located in the northeast of the state of Pará, in recent years has undergone a considerable expansion of its urban network from the growth of its peripheral areas. This is the case of the southeastern sector of the city (research locus), which counted for its structuring with a strong performance of social groups precariously

\footnotetext{
${ }^{1}$ Graduando em Geografia pela Universidade do Estado do Pará - UEPA, membro do Grupo de Pesquisa Geografia do Pará Urbano - GeoPUrb e Bolsista do Programa Residência Pedagógica. E-mail: andcarvalho.geo@gmail.com

${ }^{2}$ Graduando em Geografia pela Universidade do Estado do Pará - UEPA, membro do Grupo de Pesquisa Geografia do Pará Urbano - GeoPUrb e Bolsista do Programa Residência Pedagógica. E-mail: jhonmoraes.geo@gmail.com

${ }^{3}$ Graduando em Geografia pela Universidade do Estado do Pará - UEPA, membro do Grupo de Pesquisa Geografia do Pará Urbano - GeoPUrb e Bolsista de Iniciação Científica do CNPq. E-mail.: rayancarrera.geo@hotmail.com

${ }^{4}$ Geógrafo, Mestre em Geografia pela Universidade Federal do Pará - UFPA e Doutor em Geografia pela Universidade Estadual Paulista - UNESP/FCT/Campus Presidente Prudente. Professor Assistente IV da Universidade do Estado do Pará - UEPA, Coordenador do Programa de Pós-Graduação em Geografia da UEPA e Líder do Grupo de Pesquisa Geografia do Pará Urbano - GeoPUrb. E-mail: willame@ uepa.br
} 
included, through occupations, being the fruit of these neighborhoods Jaderlândia and Heliolândia. More recently, this southeast sector has been the focus of state housing policies and private real estate promoters, as exemplified by the Jardim das Flores project. In this perspective, the research aimed to recognize the sociospatial context of the southeastern sector of Castanhal, as well as to understand the insertion of its residents in the city. Through theoretical, documentary and field surveys, with the application of interviews, it was possible to verify that the residents of this area of Castanhal, marked by the precariousness of its infrastructure and services, also have a precarious insertion in the urban context, which is directly related to the manifestation of the process of socio-spatial segregation and, therefore, distances its residents from the right to the city.

Keywords: socio-spatial segregation, right to the city, southeast of Castanhal-PA.

\section{RESUMEN}

Castanhal se ubica en el nordeste del estado de Pará, en los últimos años pasó por una considerable expansión de su malla urbana a partir del crecimiento de sus áreas periféricas. Este es el caso del sector sureste de la ciudad (lugar de investigación), que contaba para su estructuración con fuerte actuación de los grupos sociales precariamente incluidos, por medio de ocupaciones, siendo frutos de esas los barrios Jaderlândia y Heliolândia. Más recientemente, ese sector sureste viene siendo enfoque de políticas de vivienda del Estado y de promotores inmobiliarios privados, como ejemplifica el emprendimiento Jardim das Flores. En esa perspectiva, la investigación tiene como objetivo reconocer el contexto socioespacial del sector sureste de Castanhal, bien como comprender la inserción de sus residentes en la ciudad. Por medio de encuestas teóricas, documentales y de campo, con la aplicación de entrevistas, se puede constatar que los habitantes de esa área de Castanhal, marcada por la precariedad de sus infraestructuras y servicios, poseen una también precaria inserción el en contexto urbano, lo que se relaciona directamente a la manifestación del proceso de segregación socioespacial y, por consecuente, distancia sus residentes del derecho a la ciudad.

Palavras-chave: segregación socioespacial, derecho a laciudad, sureste de Castanhal-PA.

\section{INTRODUÇÃO}

Castanhal está situada no nordeste paraense, constituindo-se como uma das principais cidades do Estado e cumprindo o papel de cidade média na rede urbana regional. De 1984 a 2016 a mesma apresentou expansão de sua malha urbana em 145\% (RIBEIRO, 2017), especialmente pela intensa urbanização da população, apresentando-se como o quinto mais numeroso município do Pará, contando com 173.149 mil habitantes (IBGE, 2010). Possui sua economia pautada na movimentação do setor de comércio e serviços, principal responsável pela estruturação de sua área de influência.A cidade expressa em seu espaço urbano o crescimento dasáreas periféricas, para isso, conta com a atuação de uma diversidade de agentes, entre os quais merecem destaqueo Estado, os promotores imobiliários (CORRÊA, 1995) e os grupos sociais precariamente incluídos 5 .

\footnotetext{
${ }^{5}$ Nomenclatura constituída a partir da concordância com a maior parte da proposição de Corrêa (1995) em relação ao reconhecimento dos Grupos Sociais Excluídos, em determinados contextos e situações, enquanto agentes modeladores do espaço urbano, contudo, absorvendo a crítica à concepção de exclusão social 
Anderson de Sousa CARVALHO, Jhon Cleber Moraes da SILVA, Rayan Valter Oliveira CARRERA, Willame de Oliveira RIBEIRO

O setor sudeste de Castanhalcontou com forte atuação dos grupos sociais precariamente incluídos, por meio de ocupações, como são os casos dos bairros Jaderlândia III e Heliolândia, apresentando características próprias de periferia urbana, concentrando pobreza, criminalidade e precários serviços (RIBEIRO, 2017). No entanto, com o passar dos anos, outros agentes adquiriram relevância no processo de modificação da área supracitada, como os promotores imobiliários privados, com a estruturação de conjuntos habitacionais e loteamentos, e do Estado, por meio de políticas habitacionais voltadas à população de baixa renda, a exemplo dos empreendimentos faixa 1 do Programa Minha Casa Minha Vida (PMCMV), que se enquadram em uma modalidade de construção que busca áreas mais distantes do centro, pelo reduzido valor das terras.

Nesse contexto, o lócus da análise foi o setor sudeste da cidade de Castanhal, mais precisamente os bairros Jaderlândia III e Heliolândia e o empreendimento Jardim das Flores. A pesquisa objetivou reconhecer o contexto socioespacial do setor sudeste de Castanhal, bem como compreender a inserção dos seus residentes na cidade.

A metodologia empregada para a realização da pesquisa está exposta nos seguintes procedimentos: inicialmente houve o aprofundamento teórico sobre a produção do espaço urbano, centro e centralidade urbana, segregação socioespacial e direito à cidade elevantamentosdocumentais sobre o setor sudeste da cidade, dando ênfase à análise dos bairros Jaderlândia III, Heliolândia e Conjunto Habitacional Jardim das Flores. Sendo esses procedimentos realizados durante o segundo semestre do ano de 2017 e primeiro semestre de 2018.

Em um segundo momento, após a sistematização dos dados obtidos, iniciou-se a segunda etapa, dedicada à coleta de dados em campo e organizada a partir dos seguintes procedimentos: mapeamento do setor sudeste da cidade; registros fotográficos; observação; análise e realização de entrevistas semiestruturadas com residentes das áreas examinadas. 12 entrevistas foram realizadas no BairroHeliolândia, em junho de 2018, contando com um total de 12 questões semiestruturadas. Do mesmo modo, 12 entrevistas semiestruturadas, em julho de 2018, foramrealizadas com beneficiários da faixa 1do PMCMV residentes no

\footnotetext{
desenvolvida por Martins (1997), que reconhece a precariedade da inserção social desses grupos ao mesmo tempo em que alerta para as suas conexões com o contexto social vigente, inviabilizando o uso do termo "exclusão". Com base nisso, optou-se pela utilização da expressão Grupos Sociais Precariamente Incluídos para se referir aos agentes modeladores do espaço urbano com atuação e vida na cidade marcadas pelo precário.
} 
Anderson de Sousa CARVALHO, Jhon Cleber Moraes da SILVA, Rayan Valter Oliveira CARRERA, Willame de Oliveira RIBEIRO

empreendimento Jardim das Flores. Cada entrevista possuía 14 perguntas. Por fim, com vistas à compreensão da centralidade do bairro Jaderlândia, foram identificados, analisados e caracterizados, em agosto de 2018, os serviços dispostos na rua Dr. Adailson da Silva Rodrigues, a principal do bairro.

O trabalho está organizado em cinco seções, além dessa introdução e das considerações finais: a primeira aborda, em termos teóricos, a produção do espaço urbano, o processo de segregação socioespacial e o direito à cidade; a segunda concentra-se na caracterização do setor sudeste de Castanhal; e as três últimas seções tratam, nessa sequência, dos bairros Jaderlândia e Heliolândia e do empreendimento Jardim das Flores, expondo os resultados empíricos da investigação realizada a partir dos objetivos anteriormente apresentados.

\section{PRODUÇÃO DO ESPAÇO URBANO, SEGREGAÇÃO E DIREITO À CIDADE}

O espaço geográfico tem sua composição associada a conjuntos de sistemas de objetos e de sistemas de ações, que se articulam simultaneamente de diferentes modos, evidenciando, assim, a dinâmica espacial (SANTOS, 2004). Os diferentes espaços se estabelecem mediante asmanifestações particulares de sistemas de objetos e de sistemas de ações, bem como de relações entre esses sistemas. Esse é o caso do espaço urbano, que ao se referir a um amplo e diverso conjunto, resguarda diferenças substanciais entre os próprios espaços inseridos nessa nomenclatura, mais uma vez, alicerçadas em particularidades dos seus sistemas de objetos e de seus sistemas de ações. Nesse sentido, Corrêa (1995, p. 7) expõe que:

O espaço urbano de uma grande cidade capitalista constitui-se, em um primeiro momento de sua apreensão, no conjunto de diferentes usos da terra justapostos entre si. Tais usos definem áreas, como o centro da cidade, local de concentração de atividades comerciais, de serviços e de gestão, áreas industriais, áreas residenciais distintas em termos de forma e conteúdo social, de lazer e, entre outras, aquelas de reserva para futura expansão.

Desse modo, o espaço urbano consistenum complexo mosaico de usos. Para Corrêa (1995) o espaço urbano é fragmentando e articulado, reflexo e condicionante social, além de ser marcado por lutas e simbolismos. É local de disputa pelas frações de terra que o compõem, como argumenta Singer (1982, p. 21): 
disputa se pauta pelas regras do jogo capitalista, que se fundamenta na propriedade privada do solo, a qual - por isso e só por isso - proporciona renda e, em consequência, é assemelhada ao capital.

Essas atividades e usos referidos pelo autor estão associados aos sistemas de ações do espaço urbano, que, assim, resulta de ações de variados agentes modeladores, entre os quais Corrêa (1995) reconhece: os proprietários dos meios de produção, os proprietários de terras, os promotores imobiliários, o Estado e os grupos sociais excluídos (aqui denominado 'grupos sociais precariamente incluídos' pelas razões já apresentadas).

Como resultado da atuação dos diversos agentes, a cidade capitalista constitui-se em espaço privilegiado para a ocorrência de diversos processos socioespaciais. Nas palavras de Corrêa (1995), “[...] os processos espaciais são as forças através das quais o movimento de transformação da estrutura social, o processo, se efetiva espacialmente, refazendo a espacialidade da sociedade" (p. 36).

Entre esses processos, especial destaque cabe à segregação socioespacial por suas grandes implicações sobre a vida social e por ser uma forte expressão das contradições da sociedade capitalista. Para Negri (2008), por meio da segregação socioespacial, a classe de maior poder aquisitivo detém o poder de produzir o espaço da cidade de acordo com os seus interesses, é essa classe que ao consumir o espaço urbano produz a segregação socioespacial. No entanto, é necessário haver cautela ao se usar o termo segregação, sendo necessário diferenciá-lo de outros conceitos:

A segregação é complexa e pode implicar ou incluir ou ter interfaces com várias dinâmicas, mas não pode ser confundida com elas: diferenciação espacial, produção de desigualdades espaciais, exclusão social e/ou espacial, discriminação social, marginalização, estigmatização territorial [...]. (SPOSITO, 2013, p. 63).

Para Sposito (2013) este conceito deve ser empregadoquando se estiver diante de separações socioespaciais radicais, havendo o rompimento entre o espaço segregado e o conjunto da cidade, prejudicando as relações/articulações intrínsecas ao cotidiano urbano.

Diversos agentes e fatores associados à reprodução do espaço urbano capitalista relacionam-se ao processo de segregação socioespacial (CARLOS, 2013), como o Estado, que por meio de políticas públicas, implanta infraestruturas de forma seletiva, remove a população pobre de áreas nobres (ou nada faz para impedir essa ocorrência), contribuindo para a alocação dos grupos de renda mais baixa em baixadas, ocupações, conjuntos habitacionais 
degradados, e outros tipos de assentamentos precários, contribuindo, nesses termos, diretamente para a materialização do processo de segregação socioespacial.

Esse processo tem repercussões diretas no sentido da negação do "direito à cidade", que diante dessa realidade se afirma enquanto luta contra as lógicas despóticas do capital e contra a regulação do Estado capitalista em sua relação com o espaço (CARLOS, 2013).

$\mathrm{Na}$ cidade capitalista, as lutas pelo espaço ganham sentido profundo, sendo produtos gerados pelas contradições que estão na base da produção do urbano. Como expõe Carlos (2013), "as lutas pela apropriação do espaço urbano que surgem no cotidiano questionam o sentido da metrópole produzida sob a égide do processo de valorização que aprofunda e encobre os mecanismos de segregação" (p. 108). Com a manifestação dessas lutas, as contradições entre valor de uso e valor de trocaficam expressas e o direito à cidade acaba se tornando o centro das disputas.

Para Lefebvre (2015) o direito à cidade manifesta-se como direito à liberdade ao habitat e à habitação, havendo diferença entre apenas estar na cidade e ter direito a ela. Incluso no direito à cidade está o direito a participar e se apropriar (bem distinto da propriedade). Desta maneira, o direito à cidade se torna uma tentativa de superação das contradições entre valor de uso e valor de troca, que, segundo Carlos (2013), se resolveria na superação daquilo que funda o capitalismo: o capital privado. Portanto, o direito à cidade aponta para:

\begin{abstract}
A negação do mundo invertido, aqueles das cisões vividas na prática socioespacial, das representações que criam a identidade abstrata (na diferença da constituição da vida como imitação de um modelo de felicidade forjado na posse de bens); da preponderância da instituição e do mercado sobre a vida; do poder repressivo que induz à passividade pelo desaparecimento das particularidades; da redução do espaço cotidiano ao homogêneo, destruidor da espontaneidade e do desejo (CARLOS, 2013, p. 109).
\end{abstract}

A superação do processo de segregação socioespacial, enquanto manifestação extremas das desigualdades socioespaciais na cidade, é pré-condição ao alcance do direito à cidade. Entretanto, não é isso que normalmente se manifesta nas cidades brasileiras contemporâneas, sejam elas pequenas, médias ou grandes, ao contrário, verifica-se uma ampliação das desigualdades e da segregação socioespacial.

Isso poderá ser verificado nos resultados obtidos a partir da pesquisa desenvolvida no setor sudeste de Castanhal, cidade que tem ampliado a extensão, a densidade, a desigualdade e 
Anderson de Sousa CARVALHO, Jhon Cleber Moraes da SILVA, Rayan Valter Oliveira CARRERA, Willame de Oliveira RIBEIRO

a complexidade do seu espaço urbano, bem como de sua inserção regional, reforçando seus papeis de cidade média ao mesmo tempo em que aprofunda suas articulações com o espaço metropolitano de Belém.

\section{CARACTERIZAÇÃO DA ÁREA DE ESTUDO}

O setor sudeste de Castanhal (Figura1) tem o iníciode produção em meados da década de 1980 e constitui-se numa das mais significativas áreas em termos de expansão urbana da cidade. Os grupos sociais precariamente incluídos são os principaismodeladores deste espaço, por meio das ocupações às margens da BR-316, principal acesso desse setor ao centro da cidade de Castanhal.

Após os anos 2000, os grupos sociais precariamente incluídos passaram a dividir o protagonismoda produção do espaço urbano no setor sudeste de Castanhal com outros agentes: empresas imobiliárias (que produziram conjuntos habitacionais, condomínios fechados e loteamentos privados) e o Estado (por meio de políticas habitacionais voltadas à população de baixa renda, como o Programa Minha Casa Minha Vida ${ }^{6}$.

\footnotetext{
${ }^{6}$ Criado em 2009, o PMCMV, segundo Cardoso e Aragão (2013), tinha como intuito inicial diminuir o déficit habitacional no Brasil e, com isso, aquecer o mercado imobiliário, dinamizando a economia do país, que enfrentava impactos gerados pela crise econômica que teve início nos Estados Unidos da América.O programa atualmente divide-se em 4 faixas de atuação: FAIXA 1: para famílias com renda de até R $\$ 1.800,00$ possuindo até $90 \%$ de subsídio do valor doimóvel, pago em 120 prestações mensais de no máximo R \$ 270 sem juros; FAIXA 1,5: para rendas de até R \$2.600,00 tendo no máximo R \$ 47.500,00 de subsídio, com 5\% de juros ao ano; FAIXA 2: para rendas de até $\mathrm{R} \$ 4.000,00$ possuindo no máximo $\mathrm{R} \$ 29.000 .00$ de subsídio, com $6 \%$ a $7 \%$ de juros ao ano e FAIXA3: para rendas de até $\mathrm{R} \$ 9.000,00$ com 8,16 de juros ao ano (BRASIL, 2016).
} 
Figura 1: Sudeste de Castanhal. Estrutura da ocupação (2018)

SUDESTE DE CASTANHAL. ESTRUTURA DA OCUPACĀO. 2018.

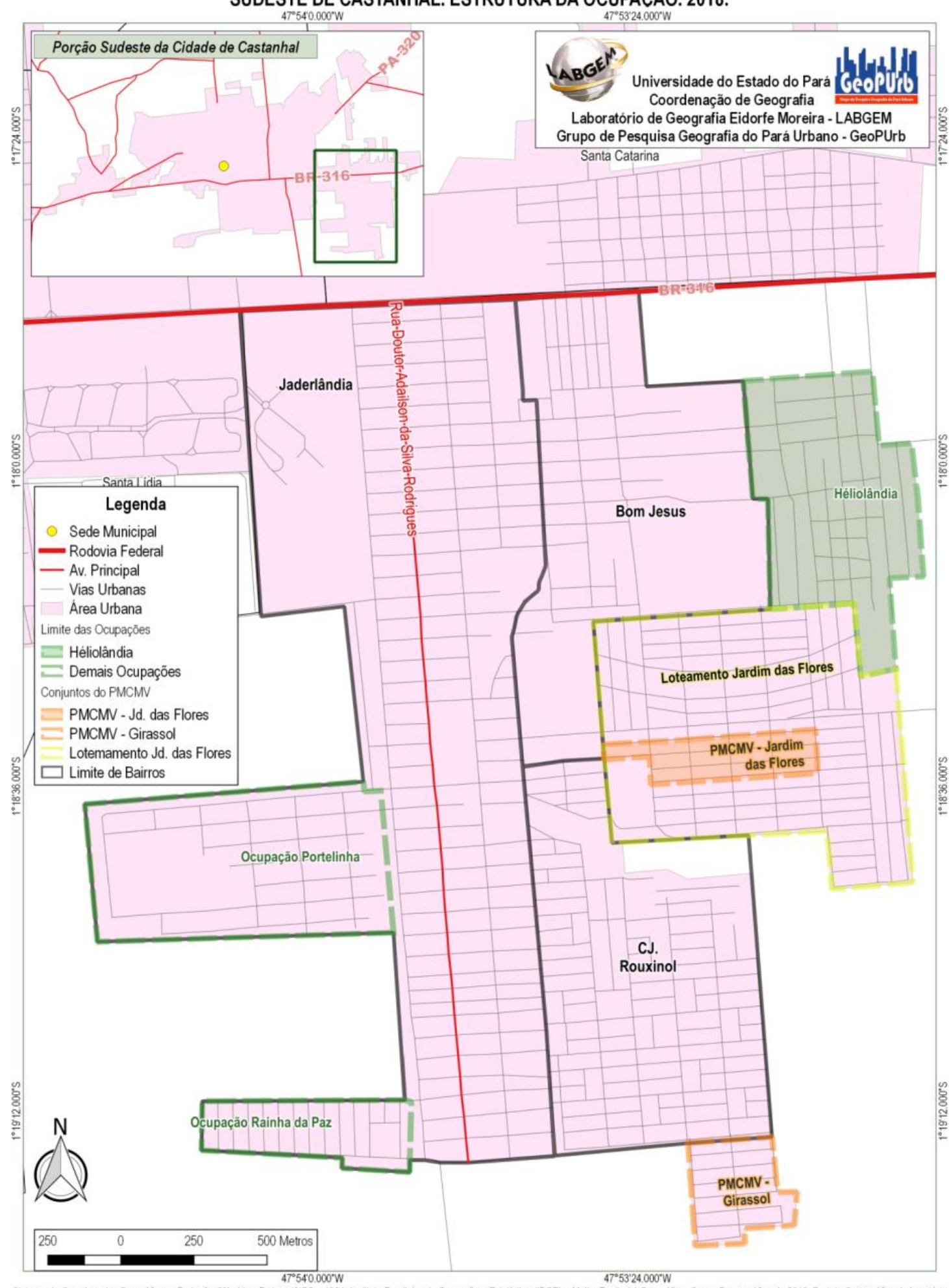

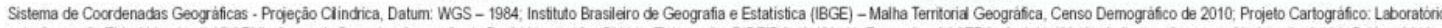

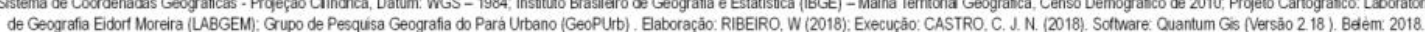

Fonte: Trabalho de campo, 2018.

Revista do Instituto Histórico e Geográfico do Pará (IHGP), (ISSN: 2359-0831 - online), Belém, v. 06, n. 02, p. 41-60, jul. / dez. 2019. 
Anderson de Sousa CARVALHO, Jhon Cleber Moraes da SILVA, Rayan Valter Oliveira CARRERA, Willame de Oliveira RIBEIRO

Uma diversidade de espaços com origens e infraestruturas diferentes compõem o setor sudeste de Castanhal e nessa pesquisa foram examinados três deles: o bairro Jaderlândia III, ocupação que demarca o início da produção do espaço nesse setor e que atualmente configura-se como o seu principal centro de serviços; a ocupação Heliolândia, de origem mais recente e com infraestrutura bastante precária; e o empreendimento do PMCMV Jardim das Flores (Figura 1).

\section{BAIRRO JADERLÂNDIA III}

O Jaderlândia III possui grande importância na estruturação do setor sudeste de Castanhal, bairroeste que tem sua gênese nas ocupações às margens da BR-316, promovida por grupos sociais precariamente incluídos. O bairro se destaca por concentrar uma variedade de comércio e serviços, especialmente na rua Dr. Adailson da Silva Rodrigues (Figuras 1 e 2). Por essas características, constitui-se como uma importante centralidade diante dos bairros e localidades do setor sudeste.

Figura 2: Jaderlândia III. Perspectiva da rua Dr. Adailson da Silva Rodrigues. 2018

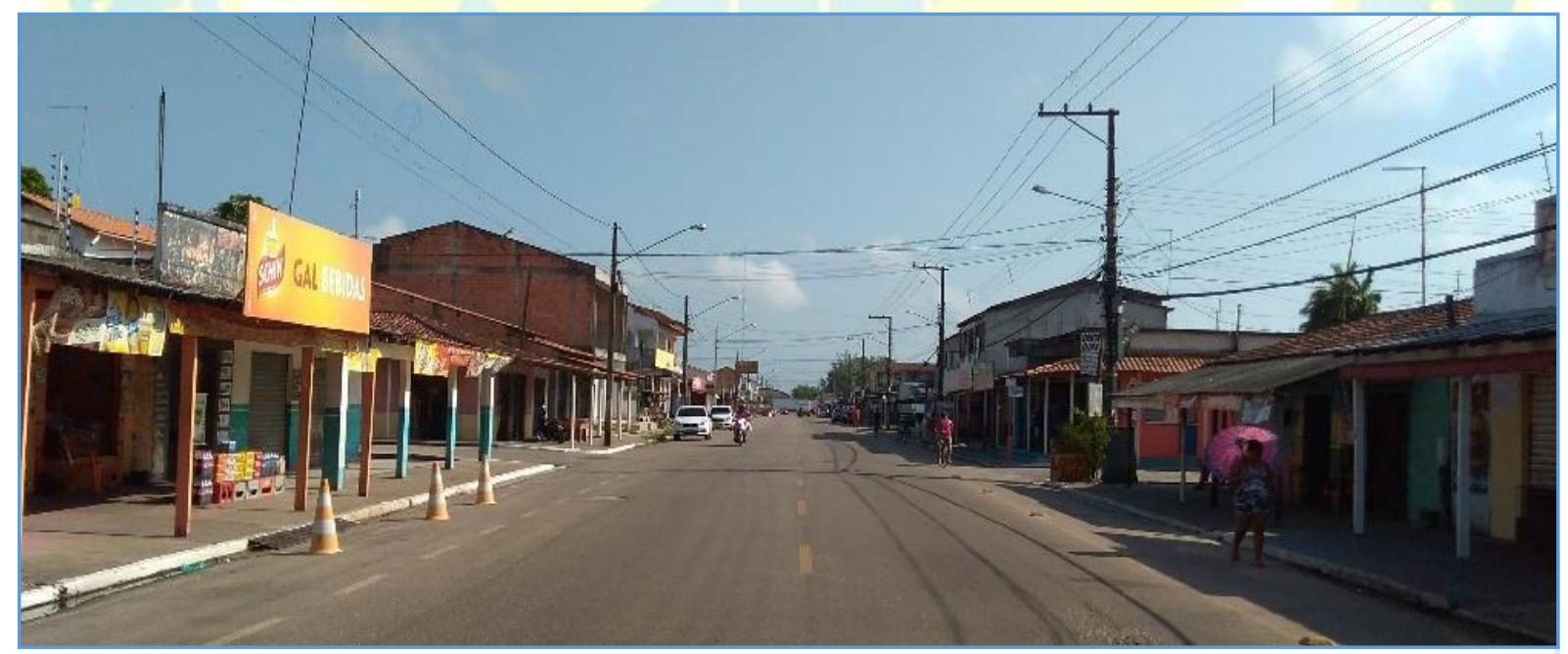

Fonte: Silva, 2018.

Nas palavras de Sposito (2013), “a centralidade [...] não é um lugar ou uma área da cidade, mas, sim, a condição e expressão de central que uma área pode exercer e representar" 
(p. 73). De acordo com Corrêa (1995), a constituição de outras áreas que oferecem funcionalidades semelhantes ao centro da cidade, como identificado no bairro Jaderlândia III, é acarretada pelo processo de descentralização, impulsionado pela expansão urbana e aumento demográfico, implicando no deslocamento ou até mesmo surgimento de atividades comerciais e de serviços em outras porções da cidade.

As atividades dispostas na rua Dr. Adailson da Silva Rodrigues se apresentam em suma em formato precário, possuindo como público alvo populações mais pobres, estando em conformidade com que Santos (2008) nomeia de circuito inferior da economia urbana, definido por ele como"atividades de pequena dimensão e interessando principalmente às populações pobres [...]" (p. 22).

No trabalho de campo no bairro Jaderlândia III, realizado em agosto de 2018, buscou-se reconhecer as características das atividades encontradas na ruaDr. Adailson da Silva Rodrigues. Os tipos de comércio e serviços identificados estão expostos no Quadro 1.

Quadro 1: Rua Dr. Adailson da Silva Rodrigues. Tipos de atividades de comércio e serviços. 2018

\begin{tabular}{|c|c|c|c|}
\hline Tipos de comércio e serviços & Total & Tipos de comércio e serviços & Total \\
\hline Alimentação & 81 & Construção & 19 \\
\hline Mercadinhos/bares & 66 & Assistência técnica de eletrônicos & 15 \\
\hline Saúde e beleza & 37 & Educação, segurança e advocacia & 10 \\
\hline Roupas e calçados & 37 & Bancários & 1 \\
\hline Automotivos & 29 & Outros & 16 \\
\hline
\end{tabular}

Fonte: Trabalho de campo, agosto de 2018.

Dentre os 311 empreendimentos de comércio e serviços identificados na rua Adailson da Silva Rodrigues, os quantitativos que mais se destacam são os relativos à alimentação e a mercadinhos/bares. Prevalece no bairro como um todo e nessa rua em particular as características do circuito inferior da economia urbana, isto é, pequenas atividades, com baixa utilização de mão de obra, quase sempre informal, reduzidas vinculações financeiras e baixa modernização. 


\section{Segregação socioespacial e direito à cidade: \\ uma análise do setor sudeste de Castanhal - Pa}

Anderson de Sousa CARVALHO, Jhon Cleber Moraes da SILVA, Rayan Valter Oliveira CARRERA, Willame de Oliveira RIBEIRO

Contudo, a simplicidade das atividades e sua precariedade não remete à baixa amplitude de atração de consumidores, ao contrário, indivíduos de todo o setor sudeste de Castanhal vão em busca de comércio e serviços na rua principal do Jaderlândia.

Isso pôde ser constatado durante o trabalho de campo realizado na ocupação Heliolândia, quando os moradores, ao serem questionados sobre o local onde realizam compras e acessam serviços, destacaram o bairro Jaderlândia como o seu principal destino, após o centro principal de Castanhal (gráfico 1).

Gráfico 1: Heliolândia: Locais onde os moradores entrevistados buscam serviços além do centro de Castanhal. 2018

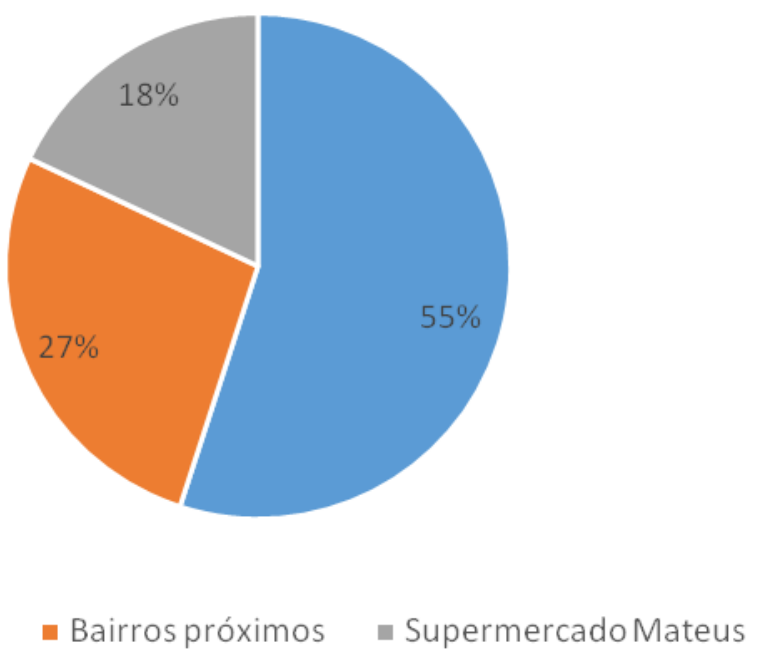

Fonte: Trabalho de campo, junho de 2018.

Da mesma forma, durante o trabalho de campo realizado no empreendimento Jardim das Flores, os moradores ao serem perguntados sobre o local onde buscam comércio e serviços, apresentaram amplo privilégio ao Jaderlândia, mesmo em relação ao centro da cidade (Gráfico 2). 
Anderson de Sousa CARVALHO, Jhon Cleber Moraes da SILVA,

Gráfico 2: Jardim das Flores: Locais onde buscam serviços os moradores entrevistados. 2018

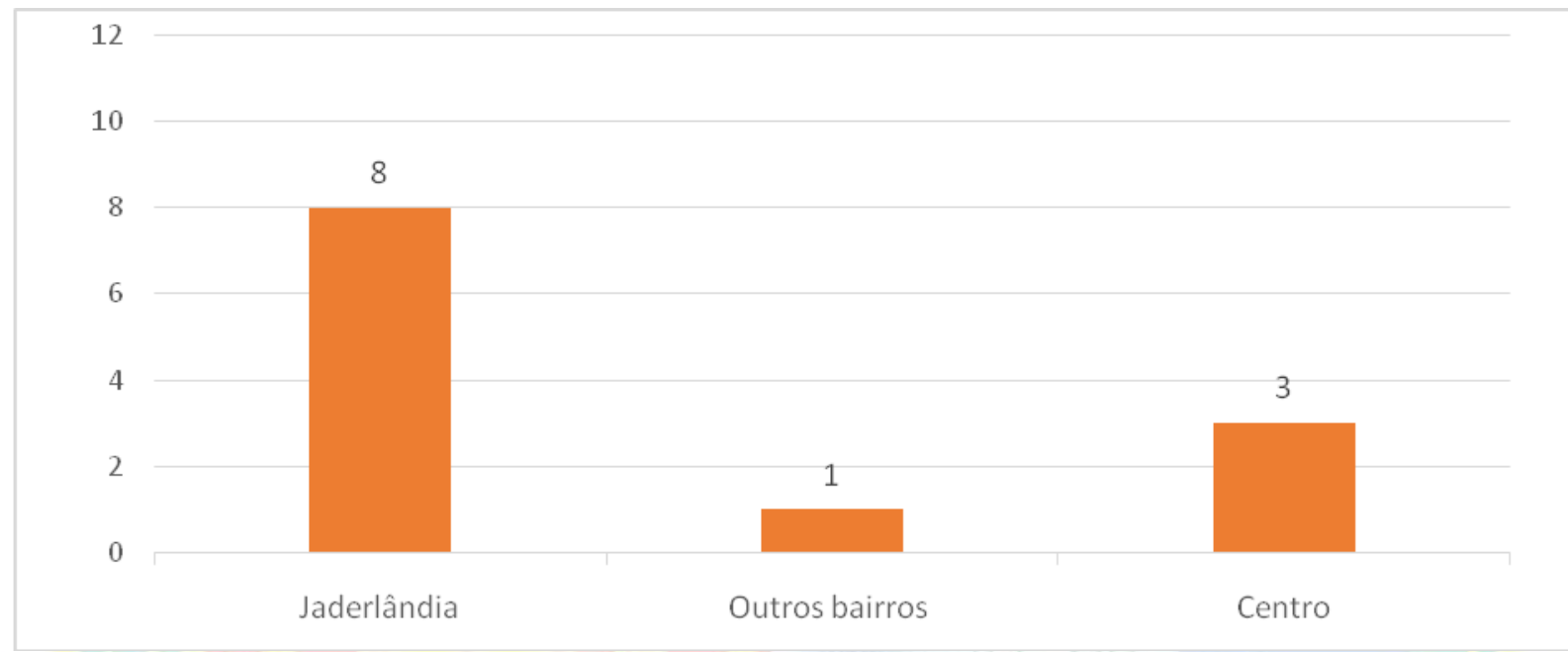

Fonte: Trabalho de campo, julho de 2018.

Tomando por base Souza (2005) e Corrêa (1995), pôde-se constatar que o bairro Jaderlândia III desempenha funções de uma localidade central intraurbana, possuindo maior atração que os bairros ao seu entorno, por concentrar uma gama de estabelecimentos que exercem atração de fluxos, isto é, que atribuem centralidade ao bairro, especialmente a sua rua principal. Diante da superação dos limites do bairro pela centralidade, que abrange todo o setor sudeste de Castanhal, a rua Dr. Adailson da Silva Rodrigues pode ser definida como um centro de bairros.

\section{OCUPAÇÃO HELIOLÂNDIA}

A ocupação Heliolândia (Figura 3) tem sua origem no contexto de expansão urbana de Castanhal, também acompanhando o eixo da BR-316, no sudeste da cidade. A partir da desapropriação de suas terras, feita pela prefeitura de Castanhal, passou a ser demarcada e considerada bairro no governo do prefeito Hélio Leite (2005-2012). O bairro em questão é em sua composição um assentamento precário (CARDOSO, 2016), originário de ocupação, com as seguintes características: ocupação do solo urbano em regime precário; falta de regularização na posse da terra; deficiência em sua infraestrutura e arruamento relativamente legível. 
Figura 3: Castanhal. Paisagem da ocupação Heliolândia. 2018

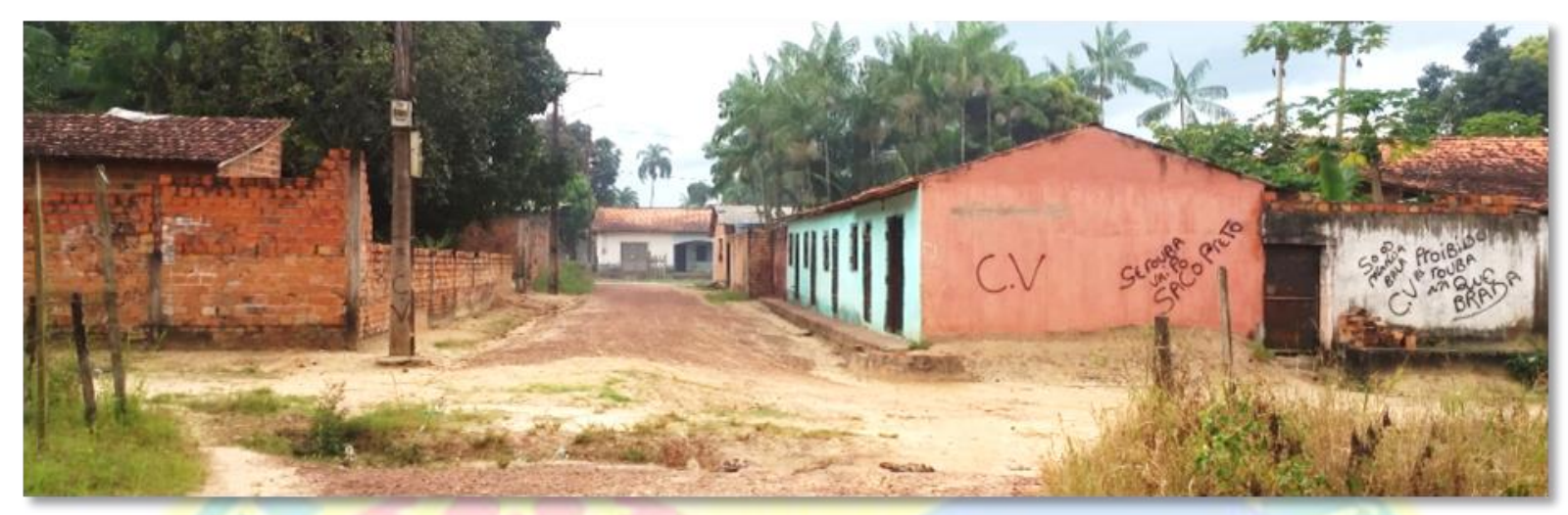

Fonte: Carrera, 2018.

Os dados presentes no quadro 2, obtidos por meio das entrevistas, são importantes para se compreender a realidade precária em que se encontram os moradores do bairro, tornando-se notória a situação da maioria dos moradores com renda abaixo de um salário mínimo e nível de escolaridade básica incompleta.

A maior parte dos moradores é composta por desempregados, além disso, a maioria dos que relataram possuir empregos, de fato, desenvolvem atividades informais, como de pedreiro, pintor e agricultor. Apenas um entrevistado afirmou ter renda de um salário mínimo completo e outro renda superior a um salário mínimo. Acompanhando as baixíssimas rendas, todos alegaram condições ruins de moradia, isto é, precariedade nos serviços próximos de suas residências, expressando as carências estruturais do bairro, como exposto no quadro 3 .

Quadro 2: Heliolândia. Escolaridade e renda dos moradores entrevistados. 2018

\begin{tabular}{|c|c|c|c|}
\hline Ensino Fundamental (Completo ou Incompleto) & 9 & Nõo responderam / Não souberam & 3 \\
\hline Ensino Médio (Completo ou Incompleto) & 2 & Menos de um Salário Mínimo & 7 \\
\hline Ensino Superior (Completo ou Incompleto) & 1 & 1 salário & 1 \\
\hline & & 2 salários & 1 \\
\hline
\end{tabular}

Fonte: Trabalho de campo, junho de 2018. 
Anderson de Sousa CARVALHO, Jhon Cleber Moraes da SILVA, Rayan Valter Oliveira CARRERA, Willame de Oliveira RIBEIRO

Quadro 3: Heliolândia. Serviços públicos demandados pelos moradores entrevistados. 2018

\begin{tabular}{|c|c|c|c|}
\hline Serviços & Quantidade & Serviços & Quantidade \\
\hline Água encanada & 1 & Posto médico & 1 \\
\hline Delegacia & 1 & Segurança & 1 \\
\hline Farmácia & 2 & Saneamento básico & 1 \\
\hline Infraestrutura & 1 & UPA 24h & 2 \\
\hline Praça para lazer & 2 & & \\
\hline
\end{tabular}

Fonte: Trabalho de campo, junho de 2018.

Das carências expressas pelos moradores do bairro, notam-se três voltadas especificamente à saúde, o que demonstra um nível de necessidade em relação ao atendimento deste serviço para os moradores. Também destaca-se a insegurança, relativa a assaltos no bairro, que se expressam de forma cotidiana. No geral, pode-se afirmar que o bairro Heliolândia se encontra em estado de precariedade, com ausência de infraestrutura, falta de serviços adequados para saúde e segurança, gerandoinsatisfação em seus moradores.

A BR-316, principal via de acesso ao restante da cidade, é vista como um problema para a maior parte dos moradores. Apontam como desvantagem o trânsito intenso e os assaltos na via, gerando insegurança. Entretanto, pôde-se constar que a falta de recursos para se locomover é o principal fator adificultar as articulações dos moradores com o restante da cidade.

Desta maneira, verificam-se estratégias dos moradoresdo Heliolândia no sentido de preencher as necessidades causadas pelas dificuldades de acesso ao centro de Castanhal.Uma delas acaba por consagrar um importante papel de centralidade ao bairro Jaderlândia III, pois com a dificuldade de locomoção, ele acaba constituindo-se enquanto o principal fornecedor de comércio e serviços a essa população, como já exposto.

Inseridos nesse contexto de dificuldade de locomoção, a maior parte dos moradores nutre um sentimento de exclusão em relação ao restante da cidade. Dentre as justificativas dos que expressam esse sentimento, ressalta-se a não entrada de serviços no bairro como táxis,moto táxis, ambulâncias e viaturas policiais. Além disso, as entrevistas destacam uma percepção de insegurança e um sentimento de medo de residentes de outros bairros em relação ao Heliolândia, que segundo os moradores, tem a ver com uma imagem de violência e 
Anderson de Sousa CARVALHO, Jhon Cleber Moraes da SILVA, Rayan Valter Oliveira CARRERA, Willame de Oliveira RIBEIRO

perigo atrelada ao bairro, cujas implicações remontam até mesmo à dificuldade de gerar empregos: Já tentei dar aula em uma escola, mas a diretora disse que não tinha mais
vagas pra dar aula, por já ter professores suficientes. Mesmo assim, ela
arranjou uma vaga para uma amiga minha, que estudou na mesma faculdade
e mesma turma que eu, só pelo fato dela morar no centro. (Informação verbal
obtida em entrevista realizada no Bairro Heliolândia - Castanhal-PA, 28 de
junho 2018).

Analisando a realidade do cotidiano desses moradores e tomando por base a concepção de segregação socioespacial (SPOSITO, 2013), é possível argumentar no sentido da vivência desse processo por parte dos moradores da ocupação Heliolândia, considerando os seguintes fatores: a visão estigmatizada sobre a ocupação, especialmente associada à violência; dificuldades de articulação com o restante da cidade; homogeneidade da composição social da ocupação; sentimento de exclusão dos moradores, de estar à margem da cidade, especialmente por sua posição nas bordas do espaço urbano.

\section{JARDIM DAS FLORES}

Outra área que se insere nasdinâmicas do eixo sudeste de Castanhal é o empreendimento Jardim das Flores, produzido segundo as diretrizes dafaixa 1 doPMCMV (Figura 4), desse modo, alicerçado em política de habitação conduzida pelo Estado. O empreendimento, apesar de ainda mais distante, localiza-se próximo ao bairro Jaderlândia III e ao lado da ocupação Heliolândia, tendo como principal via de acesso ao centro da cidade a BR-316, assim como as demais áreas estudadas.

As habitações do empreendimento são estruturadas sob as regras do PMCMV, seguindo uma lógica de construção mais simples, pautada na categoria de renda atendida pela modalidade faixal do programa, que abrange renda familiar até três salários mínimos.

O Jardim das Flores possui em sua estrutura dois modelos de construção: casas convencionais contando com duas residências construídas em um mesmo bloco; e casas em formato de apartamento, contando com quatro residências em um mesmo prédio, possuindo uma saída comum a todos. Direcionadas a pessoas com menor renda, as habitações contêm cinco compartimentos com dimensões bastante reduzidas, sendo dois quartos, uma sala, uma cozinha e um banheiro. 
Figura 4: Castanhal. Conjunto Habitacional Jardim das Flores. 2018

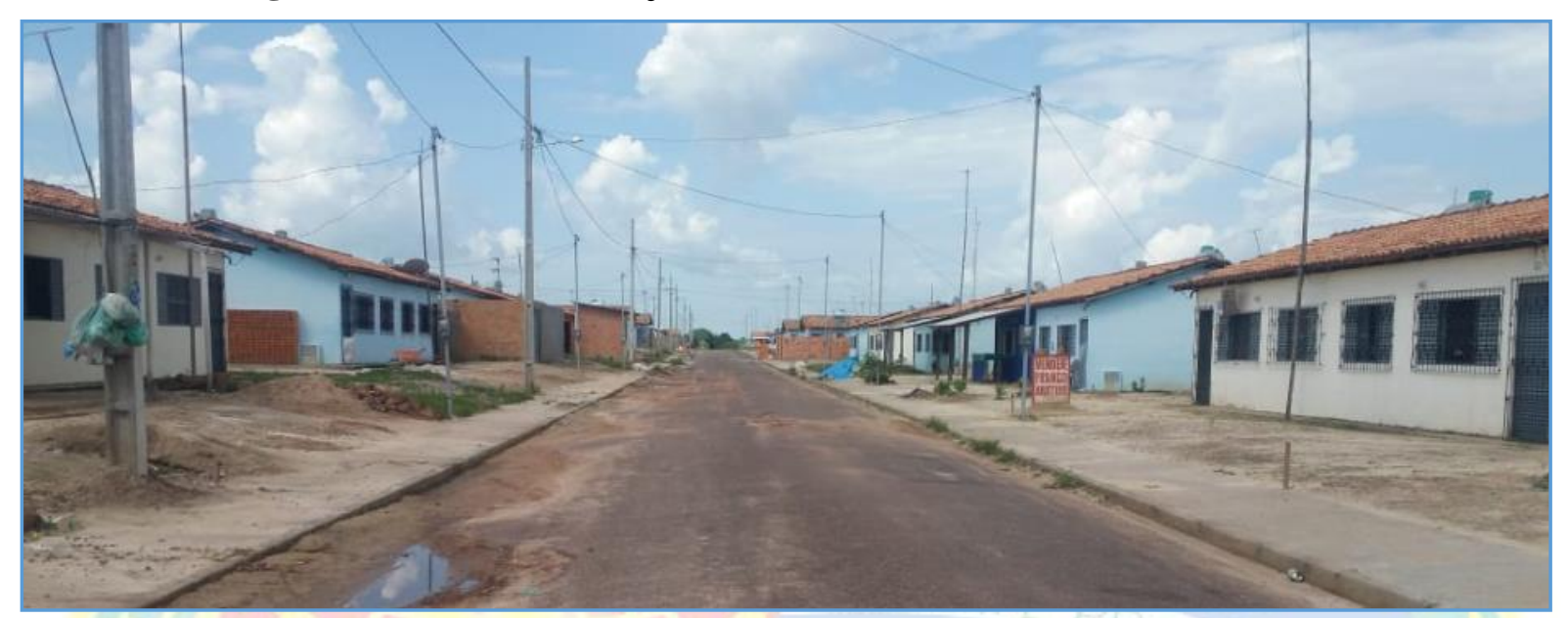

Fonte: Carvalho, 2018.

Para auxiliar na análise da área em questão, foram realizadas entrevistas semiestruturadas com os moradores. Onde muitos demonstraram certo receio em repassar informações/opiniões a respeito do empreendimento. Ao serem feitas as análises dos dados coletados, nota-se uma evidente homogeneidade de renda, garantida pelas características do próprio PMCMV, indo ao encontro da argumentação de Corrêa (1995) a respeito de áreas marcadas pelo processo de segregação socioespacial, segundo a qual, nestas áreas estão presentes fortes uniformidades sociais, em termos socioeconômicos principalmente.

Neste contexto de certa homogeneidade, poucos moradores possuem um nível de escolaridade esperado, e apenas $33 \%$ dos entrevistados possuem renda de um a dois salários mínimos, como demonstra o quadro 4.

Quadro 4: Jardim das Flores. Escolaridade e renda dos entrevistados. 2018

\begin{tabular}{|l|c|c|c|}
\hline \multicolumn{1}{|c|}{ ESCOLARIDADE } & TOTAL & \multicolumn{2}{c|}{ RENDA } \\
\hline Ens. Fund. (completo e incompleto) & 7 & Não quiseram/souberam responder & 4 \\
\hline Ens. Med. (completo e incompleto) & 4 & Contemplado pelo bolsa família & 1 \\
\hline Ens. Sup. (completo e incompleto) & 1 & Menos que 1 salário mínimo & 3 \\
\hline
\end{tabular}

Fonte: Trabalho de campo, julho de 2018. 
Nos empreendimentos da faixa 1 do PMCMV, por seremde oferta privada ao poder público, são as construtoras que definem todos os parâmetros de construção (localidade, materiais utilizados na confecção, por exemplo) e vendem integralmente para o Estado, sem riscos de inadimplência (FIX; ARANTES, 2009). Desse modo, em razão das dinâmicas do mercado, as construtoras investem o mínimo de recursos, para a maximização dos lucros (CRUZ, 2017) e, muitas vezes, ainda recebem doação do terreno no qual será realizada a construção, que, em geral, possui localização ruim no espaço urbano.

Os problemas ocasionados pela falta de infraestrutura no Jardim das Flores são bastanteenfatizados pelos moradores entrevistados, que também expõem problemas na construção das unidades habitacionais: infiltrações, desprendimento de reboco, falta de acabamento, dentre outros. Relatam os moradores que o material utilizado na confecção das casas é de baixa qualidade.

A oferta de serviços básicos como saúde, lazer, educação e segurança é bastante precária. $100 \%$ dos entrevistados relataram ausência desses serviços na área, gerando a necessidadeda procura desses serviços no centro da cidade ou em bairros próximos. Conforme Ribeiro; Lisboa e Fonseca (2015), a inserção dessas áreas na lógica urbana se faz de forma problemática, em razão de sua localização.

Outra informação expressa nas entrevistas diz respeito à dificuldade na obtenção de empregos por parte dos moradores do empreendimento (o que também foi atestado por meio das entrevistas na ocupação Heliolândia). $75 \%$ dos entrevistados afirmaram que a localização de sua moradia interfere na hora das entrevistas de empregos, gerando um sentimento de exclusão nos moradores. O trecho da entrevista retrata essa realidade: “[...] chega em um lugar onde está escrito "precisa-se de um balconista", aí você vai dizer que mora no Jardim das Flores, já gera um preconceito [...]” (informação verbal obtida nas entrevistas do conjunto habitacional Jardim das Flores - Castanhal, 18 de Julho de 2018).

Diante desse contexto e considerando que a segregação implica em um rompimento relativo entre a parte que sofre segregação e o conjunto do espaço urbano, dificultando as relações que fazem parte da vida urbana (SPOSITO, 2013), cabe reconhecer as evidênciasda manifestação do processo de segregação socioespacial no Jardim das Flores, na medida em que se verificam elementos como: visões estigmatizadas sobre o empreendimento; localização 
Anderson de Sousa CARVALHO, Jhon Cleber Moraes da SILVA, Rayan Valter Oliveira CARRERA, Willame de Oliveira RIBEIRO

distante da área central e cercada por diversas ocupações; precariedade de serviços básicos; e pelo sentimento de exclusão por parte dos moradores.

\section{CONSIDERAÇÕES FINAIS}

Diante da análise dos bairros Jaderlândia III eHeliolândia e do empreendimentoJardim das Flores, todos no setor sudeste da cidade de Castanhal, identificam-se distinções e similaridades. Um dos vetores de diferenciação está na concentração de comércio e serviços, que tem no Jaderlândia, o seu principal expoente. Com relação à infraestrutura e aos serviços básicos, também contrastes socioespaciais significativos foram verificados, uma vez que mesmo todosdispondo de precariedades estruturais e de serviçosbásicos semelhantes, Heliolândia e Jardim das Flores apresentam carências maiores, a exemplo da inexistência ou precariedade da pavimentação asfáltica e do serviço de água encanada.

As semelhanças entre os três espaços são muitas, principalmente considerando fatores relacionados ao processo de segregação socioespacial, como a visão estigmatizada sobre a área e sobre os moradores que residem nela, geralmente vistos em associação à criminalidade e à violência presentes nos espaços.

Desse modo, o processo de segregação socioespacial pode ser definido como relativo ao setor sudeste de Castanhal como um todo, gerando implicações diretas no sentido do distanciamento dessa população em relação ao direito à cidade, materializado na dificuldade de se ter acesso a serviços básicos, como educação, saúde e lazer; na precariedade das infraestruturas dos bairros e das habitações; e no sentimento de exclusão dos moradores.

Com isso, a inserção dessa população no restante do espaço urbano de Castanhal, especialmente no seu centro principal de comércio e serviços, não se apresenta de forma fluida, contando com diversos entraves que direcionam à vivência apenas do precário setor sudeste da cidade.

\section{REFERÊNCIAS}

BRASIL. Ministério do Desenvolvimento Regional. Programa Minha Casa, Minha Vida. Brasília: Ministério do Desenvolvimento Regional, 2016.2 Disponível em: <http://www.cidades.gov.br/habitacao/programa-minha-casa-minha-vida-pmcmv $>$. Acesso em: 15 jan. 2019. 
Anderson de Sousa CARVALHO, Jhon Cleber Moraes da SILVA, Rayan Valter Oliveira CARRERA, Willame de Oliveira RIBEIRO

CARDOSO, A. L; ARAGÃO, T. A. Do fim do BNH ao Programa Minha Casa Minha Vida: 25 anos da política habitacional no Brasil. In: CARDOSO, Adauto Lucio (org.). O programa Minha Casa Minha Vida e seus efeitos territoriais. Rio de Janeiro: Letra Capital, 2013, p.17-65.

CARDOSO, Adauto Lúcio. Assentamentos precários no Brasil: discutindo conceitos. In: MORAIS, Maria da Piedade; KRAUSE, Cleandro, LIMA NETO, Vicente Correia (editores). Caracterização e tipologia de assentamentos precários: estudos de caso brasileiros. Brasília: Ipea, 2016.

CARLOS, Ana Fani. A prática espacial urbana como segregação e o "direito à cidade" como horizonte utópico. In: VASCONSELOS, Pedro de Almeida; CORRÊA, Roberto Lobato; PINTAUDI, Silvana Maria (Orgs.). A cidade contemporânea: segregação espacial. São Paulo: Contexto, 2013.

CORRÊA, Roberto Lobato. O espaço urbano. 3 ed. São Paulo: Ática, 1995.

CRUZ, Sâmia Karollyne Moura da. Políticas públicas de habitação e processos socioespaciais: as complexas implicações do programa minha casa minha vida em Castanhal/PA. Trabalho de conclusão de curso (Graduação em Geografia). Universidade do Estado do Pará - UEPA, 2017, 115 p.

FIX, Mariana; ARANTES, Pedro Fiori. Como o governo Lula pretende resolver o problema da habitação alguns comentários sobre o pacote habitacional Minha Casa, Minha Vida. Correio da Cidadania. Disponível em: 〈http://www.correiocidadania.com.br〉. Acesso em: 10 Jan. 2019.

IBGE - Instituto Brasileiro de Geografia e Estatística. Censo Demográfico Brasileiro. Rio de Janeiro: IBGE, 2010.

LEFEBVRE, Henri. O direito à cidade. 5 ed. São Paulo: Centauro, 2015.

MARTINS, José de Souza. Exclusão social e a nova desigualdade. São Paulo: Paulus, 1997.

NEGRI, S. M. Segregação sócio-espacial: alguns conceitos e análises. Coletâneas do nosso tempo. Mato Grosso: Universidade Federal do Mato Grosso - UFMT, v. 8, n. 8, p. 129-153, 2008.

RIBEIRO, W. O. Interações espaciais na rede urbana do Nordeste do Pará: particularidades regionais e diferenças de Bragança, Capanema e Castanhal. 2017. Tese (Doutorado em Geografia) Faculdade de Ciências e Tecnologia, Universidade Estadual Paulista (FCT/UNESP), Campus de Presidente Prudente.

RIBEIRO, Willame de Oliveira; LISBOA, Gleyce Thamirys Chagas; FONSECA, Valdirene Martins. Entre a segregação e o desenvolvimento: o Parque dos Buritis no contexto do programa "Minha Casa, Minha Vida" em Castanhal, Pará. Boletim Amazônico de Geografia, v. 02, n. 03. Belém, 2015.

SANTOS, Milton. A natureza do espaço: técnica e tempo, razão e emoção. São Paulo: Edusp, 2004.

. O espaço dividido: os dois circuitos da economia urbana dos países subdesenvolvidos. 2 ed. São Paulo: Edusp, 2008.

SINGER, Paul. O uso do solo urbano na economia capitalista. In: MARICATO, Ermínia (org). A produção capitalista da casa (e da cidade) no brasil industrial. São Paulo: editora alfa-ômega, 1982. p. 21-36. 
SOUZA, M. L. ABC do desenvolvimento urbano. Rio de Janeiro: Bertrand Brasil, 2005.

SPOSITO, M. E. B. Segregação socioespacial e centralidade urbana. In: CORRÊA, R. L; PINTAUDI, S. M; VASCONCELOS, P. A. (Org.). A cidade contemporânea: segregação espacial. São Paulo: Contexto, 2013. 